\title{
Experiencing and managing Type 1 diabetes mellitus for adolescents in Indonesia: An integrated phenomenology and indigenous psychological analysis
}

Asril, Nice Maylani

Department of Magister of Professional Psychology, Faculty of Psychology, Universitas Gadjah Mada, Yogyakarta, Indonesia (nice.maylani@yahoo.co.id)

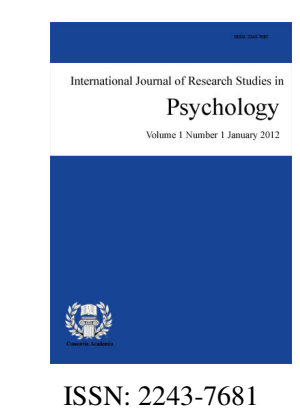

Yuniarti, Kwartarini Wahyu

Department of Magister of Professional Psychology, Faculty of Psychology, Universitas Gadjah Mada, Yogyakarta, Indonesia (kwartarini_yuniarti@yahoo.com)

OPEN ACCESS

\begin{tabular}{lll}
$\begin{array}{l}\text { Received: } 9 \text { November } 2011 \\
\text { Available Online: 21 February 2012 }\end{array}$ & Revised: 8 February 2012 & Accepted: 19 February 2012 \\
\hline
\end{tabular}

\section{Abstract}

Diabetes mellitus is a chronic disease that can be found in various age groups including teenage years. Diabetes mellitus cannot be cured but can be managed throughout life to prevent complications. Experience of self-management becomes a challenging and complex process. Psychosocial aspects are important aspects to consider in the management of adolescent self. Psychosocial aspects were examined in the study of illness representation and support from peers. The goal of this research was to explore the experience of adolescent's self-management with type 1 diabetes mellitus in the psychosocial aspects of illness representations and explain the role and support from peers on experience with type 1 diabetes. The study involved four adolescents with diabetes mellitus aged 11 to 20 years old, parents, peers, physicians, and teachers. Indigenous psychological approach with strategy indigenization from without was employed. Qualitative approach of analysis was carried out complementarily using interpretative phenomenology. In-depth interview was used for data collection used in-depth interviews. The results indicated that illness representation influenced adolescent's behavior in regulating and controlling, and the pain in order to achieve physical health and emotional well-being. Teenagers perceive diabetes as a disease of an elderly. Control and regulation of adolescent's diabetes management is highly dependent on the mother as primary caregiver and adolescent's peers.

Keywords: indigenization; phenomenological analysis; experience; psychosocial aspect; adolescent with diabetes type 1 


\section{Experiencing and managing Type 1 diabetes mellitus for adolescents in Indonesia: An integrated phenomenology and indigenous psychological analysis}

\section{Introduction}

Diabetes mellitus is defined as a disease caused by impaired insulin secretion which causes both an imbalance as well as the increase of glucose within the blood stream (Tjokroprawiro, 2004). Diabetes can be caused by complication and infection. Complication and infections which are frequently experienced by individual with diabetes are urinary infection, lung infection, foot infection, may cause abnormalities that occur in retinal blood vessels and could ended up with blindness to the sufferer (Muhlisin \& Rahmadiliyani, 2008). Diabetes cannot be cured because it is degenerative, meaning that the progression of disease will increase along with the diabetic person's age.

According to the WHO data (2010), Indonesia became the fourth country with the largest number of individuals with diabetes in the world after China, India, and America. Individuals with diabetes are spread from urban to rural areas. The total number of individuals with diabetes in Indonesia based on WHO data is currently around 8 million people, and the estimated amount exceeds 21 million inhabitants in 2025 . It is predicted that the number will continue to grow up to 350 million people by 2020 (Indonesia Diabetes, January 1, 2011). The number of people with type 1 diabetes in Indonesia is estimated to be a total of 10 percent of the overall number of diabetics (Tjokroprawiro, 2004).

The prevalence rate of diabetes in Indonesia based on data from the Ministry of Health in 2008 reached $5.7 \%$ of Indonesia's population, or approximately around 12 million people (Number of People with Diabetes, January 1, 2011). Number of People with Diabetes Articles January 1, 2011 showed that pre-diabetes prevalence rate could reach double or $11 \%$ of the total population of Indonesia in the foreseeable future. Number of People with Diabetes Articles January 1, 2011 also claimed that the prevalence of pre-diabetes can reach 20 times of that amount, or approximately $21.6 \%$. Rudjianto (2008) stated a startling fact in which $50 \%$ of individuals who are in a position of pre-diabetes will develop diabetes. Moreover, pre-diabetic individual numbers are highest in the age range of 12-17 years, with a percentage of $27 \%$ (Rudjianto, 2008).

Interview results with medical doctors in Depok II poly public health centers showed that adolescents who were found to seek treatment in public health centers due to diabetes often do not come back for the routine control. Adolescent patients who came for treatment are often in a poor physical condition with poor glucose rate. One female adolescent aged 16 years old with type 1 diabetes (YI) revealed that she had difficulties to comply with diet, exercise schedule, insulin injection schedule, and the glucose control, which has been adised by doctors and nutritionists. YI felt bored with the routine insulin injection. YI thinks that it is useless for her to comply with the diet due to the fact that her disease is incurable. YI herself has little knowledge regarding diabetes and only few of her friends know of diabetes. YI chose to hide the fact that she suffers from this type of diabetes as to avoid receiving pity from her friends if they were to know of her condition. YI perceived that diabetes self-management disrupt the times she spendt with friends. YI was often scolded by her mother in order to do the diabetic self-management. YI often forget her diet when she was with her friends. YI was worried and scared to know that some patients died due to diabetic complications.

Based on the facts above, self-management issues became an important issue for people with diabetes. Fischer et al. (1982) mentioned that one of the reasons for the emergence of a major psychological concern towards diabetes is because diabetes is a chronic disease that has a large psychological and behavioral charge. Diabetes is seen as a process of self-regulation because people with diabetes needs to do a metabollic process of self-management, such as monitoring and making adjustment the rate of blood-sugar to remain in a normal condition (Cox \& Gonder-Frederick, 1992). People with diabetes not only have to follow the instruction in 
self-management but they must also face the reality that the emergence of a complication caused by diabetes is almost inevitable. Self-management is a life-time challenging task that needs high dedication from people with diabetes (Bean, Cundy, \& Petrie, 2007). Self-management is always assisted with a change of lifestyle that is perceived to be a difficult task to be done by people with diabetes (Clark, 2011). Diabetes management can be achieved if psychological component were to be included in the diabetic treatment explicitly (Feifer \& Tansman, 1999). Existing diabetes management consists of four components, namely medical treatment, diet, exercise and monitoring blood glucose levels (Cox \& Gonder-Frederick, 1992).

Social cognitive model is a theoretical model that explained sick behavior and adherence to self-management (Hagger \& Orbbel, 2003). Individuals process the information they received based on their own experience of being sick as well as information from the environment. Result of their cognitive and thought becomes a mediator between stimulus and response within a social context (Fiske, 2004). Clark (2011) stated that poor self-management causes poor rate of blood-sugar and suffers from psychosocial problems. Malik dan Koot (2009) added that psychosocial aspect can be a protective factor towards the self-management success of a person with diabetes. That psychosocial aspect can be a form of social support (Pendley et al., 2002) and the representation of pain (Albery \& Munafó, 2009).

One of the social cognitive models used in this research was the self-regulation model of illness behavior and illness representations developed by Leventhal, Meyer, and Nerenz (Hagger \& Orbbel, 2003). Representation of pain (illness representation) is an individual response to an illness (Leventhal et al. as cited in Keogh et al., 2007) which is formed from the individual views and conceptions on the illness based on his own experience and environment (Taylor, 2006) in order to help individuals understand and manage problems arising from such sickness (Hagger \& Orbbel, 2003). Interpretation based on individuals' information is an early stage in a process of seeking help that is closely linked with their illness management (Bishop \& Converse, 2003 as cited in Hagger, \& Orbbel, 2003).

According to Leventhal and Leventhal (as cited in Odgen 2000), the representation of pain is activated in the long-term memory and its representation is formed based on comparisons between current events and pre-existing beliefs on individuals. Representation of illness becomes a schematic representation of filtering and interpreting the sources of information available on the disease and guide actions to respond to the threat of disease (Hagger \& Orbell, 2003). Representation of pain consists of five components, namely the identity, cause of pain, duration, consequences, and personal control (Leventhal et al. as cited in Moss-Morris, 2002). Inter-relation of the five components of illness representations will affect individuals in choosing coping behaviors and outcomes of coping behaviors which later would be able to predict the health status of individuals (Ogden, 2000). Representation of pain research is widely used in order to predict health status in a variety of chronic diseases such as asthma (Horne \& Weinman, 2002), diabetes (Bean et al., 2007), hypertension (Hekler et al., 2008), renal failure (Timmers et al., 2008), and osteoarthritis (Kaptein et al., 2010).

Illness representation research on people with diabetes showed a consistent result towards adherence (Mann, Ponieman, Leventhal, \& Halm, 2009), successful self-management (Bean et al., 2007) as well as a good psychological adjustment (Gois et al., 2010). Individuals who have poor control over diabetes have a different illness representation compared to individuals with good control over diabetes (Keogh et al., 2007). Representation of illness is associated with healthy forms of lifestyle and coping behaviour (Keogh et al., 2007). Representation of illness becomes a mediator variable in the relation between coping with the positive emotional wellbeing of adolescents with type 1 diabetes (Edgar \& Skinner, 2003).

Self-management is also a challenging and complex experience for teenagers with diabetes (Dashiff, Vance, Abdullatif, \& Wallander, 2008). For teenagers the daily medical care that should be done, such as glycemic control, insulin injections, diet, and exercise patterns, makes them feel burdened (Dwiardiani, 2009). Laffel, et al., (2003) showed that if children and young people with type 1 diabetes are not treated as recommended in the first year of diagnosis, it will lead to complications that may increase their difficulties in self-management 
disease. Positive attitude toward complying in self-management is highly needed for children and adolescents with type 1 diabetes in order to avoid both short-term complications such as ketoacidosis and hypoglycemia, as well as long-term complication such as liver, blindness and neural impairment (Patino, Sanchez, Eidson, \& Delamater, 2005). Self-management in adolescent becomes a complex process because it happens in a social context such as at home and at school thus these consequences must be facilitated by optimal social support (Pendley et al., 2002).

The complex self-management in adolescents is associated with adolescents' developmental stage, which is a critical period in the stages of development. This period involves changes in both hormonal and psychological conditions. These changes affect the development of adolescent's social environment. Teenagers not only interact with family but also interact with peers (Hains et al., 2006). Peers can understand the situation of adolescents better than other members of their own family (Helgeson, 1996). Time spent adolescents with their peers become more important than their time together with family (Sesma as cited in Lehmkuhl et al., 2009). The existence of many peer influences for adolescent attitudes and behavior, makes the compliance of the teenagers on lifestyle set by parents decreased (Kovacs, 1997). Adolescents often reject the standards set by older people and prefer to choose the values of peers (Santrock, 2000).

Influence of peers provides positive and negative effects on adolescents' self management (Pendley et al., 2002). Negative effects can be seen from the research of Hains et al. (2006) adolescent's who feel rejected by peers will feel stressed to the point that they experienced difficulties in compliance management. Research done by Lemhkuhl et al. (2009) suggests that social activity with peers can interfere with self-management of adolescents with diabetes, especially on dietary adjustment. This study also showed that the most difficult task for adolescents with diabetes is when they have to tell their friends that they suffer from diabetes.

However, the positive effect of peers is also shown by many other studies. The role of peer support in adolescents who bear the disease can reduce feelings of isolation and lonely; provide information about access to health services and encourage healthier living practices (Cohen, Gottlieb, \& Underwood, 2000). The role of the presence of peers can also be seen in adolescents with diabetes. Adolescents with type 1 diabetes feel the support from their peers better than children of school age (Pendley et al., 2002). Peer support has three main functions such as helping the management of diabetes in daily activities, social and emotional support, and being facilitator with clinical care (Fisher, Earp, Maman, \& Zolotor, 2009).

Heisler (2007) showed that high social support from peers, especially support in keeping the way of life, is associated with good self-management in adolescents with diabetes. Peers who understand the disease of diabetes will support adolescents with type 1 diabetes to comply with the pattern of their diet, exercise, and treatment (Lehmkuhl et al., 2009). Adolescents with type 1 diabetes prefer to interact with peers who understand the causes of illness and know their diets (Lehmkuhl et al., 2009). Persons with diabetes who get support from their peers, have increased results of biophysical and psychosocial (Paul et al., 2007), including representation of pain (Keogh et al., 2007).

Support from peers is one form of structural support, which is a support given by an individual's significant figure (Cohen et al., 2000). Support from peers is a process of social relationship with peers who can support health and welfare (Paul, et al., 2007) including the availability of emotion, hope, and help information provided by peers (Dennis as cited in Paul, et al., 2007). Peers can understand well the situation of individuals compared to other members of his own family or social networks, which might have made the individual feel uncomfortable in the issue or may interfere in providing support (Helgeson as cited in Paul, et al., 2007).

Based on the findings of previous studies, psychosocial aspects became an important aspect that needed to be considered in order to understand the experiences of adolescents with type 1 diabetes in conducting self-management. Psychosocial aspects studied in this research were adolescent self-management experience that would be explored by understanding the illness representation and support from peers. This study aimed to explore the experience of self-management adolescents with type 1 diabetes in psychosocial aspects of illness 
representations and explain the role and support from peers towards the self-management of adolescents with type 1 diabetes. In order to know the experience of adolescents' self-management to type 1 diabetes, researcher formulated the following research questions:

1. What is adolescents' general perception on their self-management experience, with type 1 diabetes in psychosocial aspects?

2. What is the role of illness representations and support from peers towards the self-management of adolescents with type 1 diabetes?

\section{Methods}

This study used two research approach done complementarily. The research approach used is indigenous psychology and interpretative phenomenology. Through the indigenous approach, researcher sought to understand adolescents' self-management experience in type 1 diabetes, and how adolescents interact with others within their cultural context (Kim, Yang, \& Hwang, 2006). Indigenous psychological researches lead to the strategy of indigenization from without. According to Tenth, Enriquez (as cited in Kim, Yang, \& Hwang, 2006), indigenization from without is similar to ethical approach. Within indigenization from without, researcher creates a more systematic knowledge that may be tested both theoretically and empirically on the psychosocial aspects of self-management experience according to the local cultural context.

Interpretative phenomenological analysis approach is used to explore the meanings of individual experience, and how the people involved in an in-depth experience (Lyons \& Coyle, 2007). The end result of two complementary approaches is the new knowledge regarding the experience, of self-management on adolescents' type 1 diabetes in relation to the psychosocial aspects in accordance to local cultural context.

\subsection{Participants}

\section{Table 1}

The study participants

\begin{tabular}{|c|c|c|c|c|}
\hline Items & KM Participant & DP Participant & KN Participant & RJ Participant \\
\hline Sex & Male & Male & Male & Female \\
\hline Age & 17 years old & 17 years old & 21 years old & 18 years old \\
\hline Birth Order & $\begin{array}{l}\text { The } 3^{\text {rd }} \text { child from } 3 \\
\text { brothers }\end{array}$ & $\begin{array}{l}\text { The } 4^{\text {th }} \text { child from } 4 \\
\text { brothers }\end{array}$ & $\begin{array}{l}\text { The } 3^{\text {rd }} \text { child from } 3 \\
\text { brothers }\end{array}$ & $\begin{array}{l}\text { The } 1^{\text {st }} \text { child from } 2 \\
\text { brothers }\end{array}$ \\
\hline Parents' Occupation & $\begin{array}{l}\text { Father: does not work } \\
\text { Mother: pastries sellers } \\
\text { in the market }\end{array}$ & $\begin{array}{l}\text { Father: Lecturer on } \\
\text { farms } \\
\text { Mother: High school } \\
\text { teacher }\end{array}$ & $\begin{array}{l}\text { Father: working in the } \\
\text { field of tourism } \\
\text { Mother: professor of } \\
\text { medicine }\end{array}$ & $\begin{array}{l}\text { Father had died, used to } \\
\text { be an importer } \\
\text { Mother: importer }\end{array}$ \\
\hline \multirow{2}{*}{$\begin{array}{l}\text { Diagnosis of diabetes } \\
\text { Complication }\end{array}$} & since 2008 & since 2006 & since 2005 & since 2008 \\
\hline & $\begin{array}{l}\text { Ketoacidosis (blood } \\
\text { sugar levels above } 400 \\
\mathrm{mg} / \mathrm{dl} \text { ), resulting in a } \\
\text { coma for } 7 \text { days }\end{array}$ & $\begin{array}{l}\text { Ketoacidosis (blood } \\
\text { glucose level above } \\
500 \mathrm{mg} / \mathrm{dl} \text { ) into a coma } \\
\text { for } 6 \text { days }\end{array}$ & $\begin{array}{l}\text { Tubitus wound after } \\
\text { appendectomy surgery, } \\
\text { hospitalized for } 2 \text { weeks } \\
\text { due to ketoacidosis } \\
\text { (blood sugar levels } \\
\text { above } 300 \mathrm{mg} / \mathrm{dl} \text { ) }\end{array}$ & $\begin{array}{l}\text { Ketoacidosis (blood } \\
\text { glucose } 1000 \mathrm{mg} / \mathrm{dl} \text { ), } \\
\text { which resulted in coma } \\
\text { for } 6 \text { days }\end{array}$ \\
\hline Significant others & $\begin{array}{l}\text { Father } \\
\text { Mother } \\
\text { Medical doctor } \\
\text { Nurse }\end{array}$ & $\begin{array}{l}\text { Mother } \\
\text { Oldest sibling } \\
\text { Peers } \\
\text { Teacher } \\
\text { Medical doctor }\end{array}$ & $\begin{array}{l}\text { Mother } \\
\text { Second older sibling } \\
\text { Peers }\end{array}$ & $\begin{array}{l}\text { Mother } \\
\text { Peers }\end{array}$ \\
\hline
\end{tabular}

Participants were selected using purposive sampling, in which the characteristic of participants was determined and known (Lyons \& Cole, 2007) so that participants who were selected would be able to provide 
information regarding the special experience that will be studied (Smith, Flowers, \& Larkin, 2009). Participants in this study were 3 male adolescents and one female adolescent having type 1 diabetes. Participants diagnosed with diabetes mellitus type 1 is more than a year and find it difficult to comply with self-management of diabetes (blood sugar control, insulin injections, diet, and exercise patterns).

Participants were recruited based on voluntarily based and predetermined criteria. Researchers initially met participants through direct meetings to ask for their willingness to participate in this study. Informants of this study were the adolescents' significant others, namely their doctors, teachers, parents, siblings, and peers. These significant figures were involved as informants to see their involvement in the adolescent's experience of self-management with type 1 diabetes. Significant figures as well as a source of comparative data.

\subsection{Tools and Materials}

The data collection used in-depth interview guide. In-depth interview guide was developed based on research aim, research question, theoretical review and previous studies in order to obtain more specific information. A representation of illness interview guide was arranged in order to uncover the experience of adolescents on diabetes self-management using the five components of illness representation theory of Leventhal Self Regulation Model (Leventhal et al. as cited in the Moss-Morris, 2002). The interview guide is given to the representation of ill adolescents with type 1 diabetes, parents and brothers. The interview guide for the medical doctors and teachers have also been prepared aiming to explore the experience of adolescents with diabetes self-management.

\section{Table 2}

Research Map

\begin{tabular}{|c|c|c|c|c|}
\hline $\begin{array}{c}\text { Aim of } \\
\text { Research }\end{array}$ & $\begin{array}{l}\text { Research } \\
\text { Approach }\end{array}$ & Participants & $\begin{array}{c}\text { Data Collection } \\
\text { Tool }\end{array}$ & Sub-Goal \\
\hline \multirow{6}{*}{$\begin{array}{l}\text { Exploring the } \\
\text { experience of } \\
\text { self-management } \\
\text { and explain the } \\
\text { role of illness } \\
\text { representation and } \\
\text { peer support in } \\
\text { adolescents } \\
\text { self-management } \\
\text { with type } 1 \\
\text { diabetes }\end{array}$} & $\begin{array}{l}\text { Indigenous } \\
\text { approach and } \\
\text { interpretative } \\
\text { phenomenological } \\
\text { analysis }\end{array}$ & $\begin{array}{l}\text { Adolescents with } \\
\text { type } 1 \text { diabetes }\end{array}$ & $\begin{array}{l}\text { Representation of illness } \\
\text { interview guide } \\
\text { Interview guide peer } \\
\text { support Talking About } \\
\text { Diabetes Survey, } \\
\text { Adolescent } \\
\text { (TADS-A) }\end{array}$ & $\begin{array}{l}\text { Participants' response to illness } \\
\text { Behavioral self-management } \\
\text { Support from peers and their role in } \\
\text { diabetes management }\end{array}$ \\
\hline & & Parents & $\begin{array}{l}\text { Representation of illness } \\
\text { interview guide }\end{array}$ & $\begin{array}{l}\text { The response of family members to the } \\
\text { participants' disease } \\
\text { Participants self-management behavior in } \\
\text { family setting }\end{array}$ \\
\hline & & Relative & $\begin{array}{l}\text { Representation of illness } \\
\text { interview guide }\end{array}$ & $\begin{array}{l}\text { The response of family members to the } \\
\text { participants' disease } \\
\text { Participants self-management behavior in } \\
\text { family setting }\end{array}$ \\
\hline & & Peer & $\begin{array}{l}\text { interview guide peer } \\
\text { support Talking About } \\
\text { Diabetes Survey Peers } \\
\text { (TADS-P) }\end{array}$ & $\begin{array}{l}\text { Peers' experience in interacting with } \\
\text { participants }\end{array}$ \\
\hline & & Doctor & Doctors' interview guide & $\begin{array}{l}\text { Participants self-management experience } \\
\text { from the viewpoint of physicians }\end{array}$ \\
\hline & & Teacher & $\begin{array}{l}\text { Teachers' interview } \\
\text { guide }\end{array}$ & $\begin{array}{l}\text { School's response towards participants' } \\
\text { disease } \\
\text { Participants' self-management experience } \\
\text { in Schools settings }\end{array}$ \\
\hline
\end{tabular}

A support interview guide from peers was adapted from an interview guide on Talking About Diabetes Survey, Adolescent and Peer Versions (TADS-A; TADS-P). TADS-A explore and understand the experiences of 
adolescents related to support from peers and their roles on diabetes management. TADS-P explore and understand the experience of interacting with peers in adolescents with diabetes (Lemhkuhl et al., 2009). The theory used in preparing the interview guide aimed to understand the extent to which involvement of theory can explain the experience of adolescents self-management with type 1 diabetes in the context of their culture on a regular basis (Kim, Yang, \& Hwang, 2006).

\subsection{Research procedures}

Preliminary data was taken from the preliminary interviews on one participant in order to know facts that occur in the field. The study began with the selection of participants using purposive sampling method. The researcher explained to prospective participants who were adolescents with diabetes, parents, siblings, and their peers about the principle of willingness and informed consent for research participants.

A zig-zag pattern was implemented in the study (Creswell, 1998), in which researchers seek information in the field, trying to identify it and if it was less adequate then the investigators would re-enter the field to explore the data. Researchers identify the data back to find a situation of saturation data or exhausted. Researchers recorded the interview using a voice recorder. Investigators documented data in the form verbatim. Researchers also documented data, which were considered to be important in the field as a secondary data related to the purpose of research.

\section{Data Analysis}

The data analysis of indigenization from without approach (Yuniarti, 2010) begins with recording and transcribing participants and informants' interviews. Researchers identified themes that emerged relating to representation of illness and support from peers in relation to the experience of adolescents' with diabetes self-management. Researchers also identified the themes that emerged related to local knowledge and beliefs about the experience of adolescents with diabetes self-management and relationship with psychosocial aspects. Further, researchers looked for the involvement of themes related to theory with themes related to local knowledge and belief. The integration between the two themes was then forming a new theory model of psychosocial aspects in the experience of self-management adolescents' with type 1 diabetes mellitus, which was bond the local cultural context. The next steps interpretative phenomenological analysis of data (Smith, Flowers, \& Larkin, 2009) was described as following part:

\subsection{Read and re-read the transcript of the data}

The researcher read and reread the transcript data in order to gain understanding and make sure the meaningful parts of participants' story can be interpreted. Re-reading may also help researchers understand how the rapport and trust between researchers and participants started to appear and be more aware of rich and detailed meaning within the elements of the story.

\subsection{Start recording}

This step was quite detail and consumed a lot of time. Researchers noted anything interesting from the transcript. Researchers examined the semantic content language used by participants. Researchers identified specific things on how participants speak, understand, and think related to experience under the study of interest. The recording was divided into three main focus for the sake of illustration, namely:

1. Descriptive comments focused on recording the stories that participants said during the interview.

2. Linguistic comments focused on the exploration of the specific language used by participants. The use of words, pause within the conversation, laughter, repetition of words, tone of voice, speech fluency was noted by researchers. 
3. Comments focus on the conceptual blend of interrogative and the conceptual level. Researchers confirmed the story which part becomes the data and which part of the story was associated with the next question.

\subsection{Determining the essential themes}

Identify comments that have been recorded into the important themes that have been determined. This important theme was able to present as many possible symptoms or experiences examined. These themes are important not only the original words and thoughts by participants but be more the analysis of interpretation by story told by participants.

\subsection{Finding the relationship of the essential themes}

Researchers mapped out how the relationship between the essential themes that have been determined. Researchers then validated and analyzed the relationship between these themes.

\subsection{Switching to participants' past experience}

The steps carried out started from the first step to the forth step above.

\subsection{Seeing the same pattern among the by participants experience}

This step explore the relationship between participants' experiences, how a theme from one participant helps explain the experience of other participants, and which is the most common themes that emerged. The end result is a description and explanation of the dynamics of the experience of by participants. Further, researchers combine the data analysis of indigenization from without approach and interpretative phenomenological analysis of the results in order to gain a single final result which is a new model of knowledge that has been tested both theoretically and systematically on the psychosocial aspects of adolescents' self-management experience with type 1 diabetes mellitus.

\section{Results and discussion}

The interview result based on the four participants' self-management experiences who were involved in this study created a series of themes that reflects the goal of the study. The aim of the research was to explore the self management experience of adolescents with type 1 diabetes within its psychosocial aspect as well as explain the role of illness representation and peer support towards adolescents with type 1 self management. In accordance with a predetermined limitation of the study, the themes that were identical and mutually reinforcing were then tied into five broad categories. These categories are subjective pain representation of adolescents with type 1 diabetes, feeling unwanted, self that have not understood the pain and control conditions, living with an unwanted self when alone, and living with an unwanted self when with others.

\subsection{Subjective Pain Representation of Adolescents with Type 1 diabetes}

All the participants perceived type 1 diabetes based on their own experiences and information that exist in the environment to assist them in understanding and managing issues arising from their diabetes. This finding is consistent with the notion of representation pre-existing illness. Representation of pain is an individual response to an illness (Leventhal et al. as cited in Keogh et al., 2007) that is formed from the individual views and conceptions about the illness of his own experience and environment (Taylor, 2006).

Based on Leventhal et al. (as cited in Moss-Morris, 2002), the representation of illness consists of five components, namely the identity, cause of pain, duration, consequences, and personal control. The five components of illness representations differ with the findings in the field. Components of illness representation 
that were identified based on interviews with all participants were namely identity, duration, cause, personal control, environmental control, and consequences. The identities of the disease are the name of the disease and symptoms associated with the given name. Duration of beliefs is how long the pain will end. The cause of the attribution of the disease is characterized by beliefs on the causes of disease. Personal control is the belief of how far the disease or symptoms can be controlled and changed by the ability of the self. Belief on environmental control is how far the disease or symptoms can be controlled and changed with the help of health workers and people nearby. The consequence is the effect of disease on physical, psychological and social function.

Representation of pain is associated with other forms of health behavior and coping behavior (Keogh et al., 2007). The results are in line with the findings in the field. The number of symptoms experienced by the participants made participants perceived their illness as a chronic illness. This encouraged participants to seek knowledge and information on the disease that they bear in order to gain understanding of the disease. This understanding that participants have is less supported by the environmental representation of illness. This situation made participants perceived the consequences and seriousness of diabetes as a serious and scary situation. This encouraged the formation of perceptions of poor control treatment, boring, and limits the activities of participants. Participants who represent their illness as a chronic disease also resulted in them having low intention in maintaining their control treatment. Participants tended to rely on the use of insulin as an outlet to control their blood sugar levels. The number of symptoms and consequences that perceived as serious and scary situation helped shape the representation of emotion. Participants felt the fear, shame, sadness, and loneliness. Participants did not understand their ill condition thus participants mark their self after they were sick as unwanted self. This representation of emotion shaped participants' poor understanding on the disease and affects in the adolescents' implementation of control treatment.

Formation of illness representation in all participants was also influenced by the participants' belief and cultural values, religious value, educational background, and economic status. Belief and cultural local values proved to have influenced a person's perception on the seriousness and susceptibility of an illness (Kim, Yang, \& Hwang, 2006). Based on the participants' local beliefs, diabetes was identified as an elderly disease. People in the surrounding were "surprised" that diabetes could also happen to adolescents; they looked at it as a strange phenomenon. This situation caused participants to face similar response from the environments such as being questioned and pitied due to their diabetes. KM participant has experienced rejection from their peers due to having diabetes. His surrounding environment view diabetes as a contagious disease. His family was also getting hints from the surrounding environment because they cannot take care of children so that children have to suffer ill parents (illness for elderly). This situation makes Participants' KM and family to withdraw and hide the use of insulin injections to avoid the negative consequences of the environment. The lack of public knowledge about diabetes type 1 , caused negative response from the environment.

The cause of diabetes from all participants was still unknown it might be due to errors in diet, heredity, and the presence of virus in the pancreas. Participant RJ and KN suspected offspring as one of the cause of their illness diabetes because their grandmother also had diabetes. Participant DP and RJ hope that someday pancreas transplants could be performed. These expectations also arise due to feeling bored with the routine use of insulin. Participant DP, RJ, and KM have a belief that diabetes could be cured even though they had met physicians who stated that diabetes could not be cured. KN participant believed that diabetes was indeed pain that would always be suffered.

Alternative medicine in the form of traditional medicine is also a treatment option that can bring hope for the participants to recover. Participants RJ, DP, KM had tried traditional medicine because they have the desire to heal, even though they know that diabetes is incurable. Alternative medicine is used without consulting to a doctor. In the other hand, KN participant did not use alternative treatment because her mother and brother who came from a medical background forbade him from doing so. The prohibition from her mother and brother did not dampen KN's confidence in the traditional medical approach that said that stomping the foot to the ground in the morning can help lower blood sugar. 
DP participant confidence to recover arises because of the experience of a coma for 7 days due to complications of diabetic (ketoacidosis) which was indicated by hyperglycemic and the presence of ketonuria. The process of waking up from a coma on DP participant viewed as a miracle from God because doctors had actually diagnose the situation of DP as a coma, which could not be helped and even when conscious DP could experience paralysis or loss of memory. The diagnosis was not proven, DP participant somehow slowly returned to normal situation. DP participant considered that the miracle has raised hope for him that there was another miracle that would be accepted as sincere and willing to surrender himself. RJ belief that he would be recovered because in his religion (Islam) stated that all the diseases that exist in this world must have a cure. This made RJ had high hopes that eventually there would be a cure for diabetes. KM confidence grew due to seeing a television ad on traditional treatment. From the advertisement, many diabetic patients can be cured, but due to lack of funding he had not tried to take one of the traditional treatments. KN believes that diabetes will be experienced in a lifetime and the only way to be able to live with diabetes is by controlling blood sugar. This was because of the education background of his family's members who are engaged in the world of health. KN's mother is a pharmacist and is currently a lecturer at the Faculty of Medicine and KN second sister is a medical doctor. KN's mother and sister gave evidence of diabetes patients who can live without complications by regulating their blood sugar. This condition assured $\mathrm{KN}$ that controlling blood sugar is a way to live with of diabetes.

Management of diabetes with blood sugar control, diet, exercise, and insulin syringes was recommended by doctors to all four participants. In the implementation of diabetes management involved not only the participants themselves but also required the active involvement from many of participants' significant others. Significant others involved family, peers, and teachers. participant at the age they require strict monitoring and direct referrals from significant figures in implementing diabetes management (Pendley, et al., 2002)

Each member of the family took an important role in providing support for the implementation of the management of participants' diabetes. Pastoral care from the mother becomes an important process for adolescents with type 1 diabetes. This was because the mother was a primary nurse in management of diabetes from all four of participants. Mother plays an important role in controlling the compliance of participants to run the management of diabetes (Gonder-Frederick et al., 2006). Mother is often a person who's prone to feeling anxious and afraid of parting with her son who had type 1 of diabetes (Dashiff, Vance, Abdullatif, \& Wallander, 2008). Diabetes also leads to changes in habits, additional responsibilities, and changes in the roles of each family member. These changes often led to conflict within the family for all four participants.

Added with participants' developmental tasks, who are currently at an adolescence developmental stage, which is a critical period within their developmental stages. A time of hormonal and psychological changes (Santrock, 2000). On one side participants' began to establish autonomy and integrity in the decisions taken. On the other hand they still need support from family to run the management of their diabetes. This situation ultimately led to the conflict to abide by participants' in management of diabetes. Not to mention the participants' widespread social environment such as having peer groups that are more understanding and who are able to comprehend them. These findings suggest that diabetic teenagers need a friend (buddy) in the implementation of the management of their diabetes. In other words, the control in diabetes management involves the implementation of the personal control of persons with diabetes and control from environment. Control from environment carried out by the significant figures from participants' parents, siblings, and peers. This condition is consistent with the findings from the study Pendley, et al. (2002) which states that the environment around the individual has an important role in diabetes management.

The hardest consequences experienced by participants when diagnosed with diabetes were almost the same: three from the participants (DP, RJ, KM) lapsed into a coma due to complications of ketoacidosis. This coma brought one of the participants into a near death experience. DP participants' blood sugar levels were not stable during the time that DP was in a coma. Physicians involved in the treatment of this condition admitted that it was beyond the general condition which is common in patients with coma. Suspicion involvement of other sciences 
(magic) any issue presented by the physician during the DP into a coma. DP also felt that there were two figures robed guard during the coma. Other experiences were also faced by participants RJ and KM. They had the same experience as regular night's sleep while experiencing coma. When they woke up from a coma it felt like waking up from a routine night sleep in general. Participant $\mathrm{KN}$ was the only participants that did not experience a coma. But he should not eat rice for two months to help control his blood sugar.

\subsection{Feeling unwanted}

Three participants RJ, KM, KN when first diagnosed with diabetes raises ordinary sense due to at first they did not have enough knowledge about diabetes. When they start to get further information about the complications of diabetes that they might faced they started to feel scared, anxiousness, depression, distrust, and sadness in them. In contrast to DP participant who initially felt scared, depressed due to a temporary paralysis caused by complications, but in line with a recovery emerging sense of resignation. Feelings of resignation arose because she was feeling grateful to God for the miracle he made it through the trials are given in succession waking up from a coma, memory back, back to work, and kidney conditions improved. During the management of with diabetes, all participants felt the shock, discomfort while undergoing treatment, should be scared at the beginning of the diet.

In addition some participants experienced difficulty in the diet, such as difficulty in controlling self, controlling appetite, regulating the type of food, the amount of food, and feeling bored and fed up with the recommended food. Another difficulty experienced by patients is the presence of indiscipline in practicing exercise. KN was not even abstained from food and certain beverages that is best avoided by patients with diabetes, he still smoked, ate chocolate, and drinking alcoholic beverages. $\mathrm{KN}$ tried to rationalize that smoking and drinking alcoholic beverages are justifiable. Participant KN was even willing to regurgitate his food after he smoked to help reduce nicotine levels in his lungs. The interviews found results consistent with the results of research conducted by Fisher et al. (1982) and Hasanat and Ningrum (2009) which states that diabetes is a chronic disease that has great psychological and behavioral burden.

\subsection{A self who have not understood and control the pain condition.}

All the participants are less able to understand and control with diabetes as a result from the consequences experienced after being diagnosed as having diabetes type 1 . In early diagnosed type 1 with diabetes showed that those living with diabetes and feelings affect how you view them in understanding themselves as human being. This happens due to the consequences from a diagnosis of with diabetes helped change their habits and a routine. Even KN participant have confidence that by spewing his food after exercise someday help lower blood sugar levels and reduce the effects of nicotine that breathed.

In the course of diabetes, all participants seemed to reject it, either directly or indirectly. This avoidance was one of self-defense mechanism that was used, so that they were more comfortable with the changes that occur due to diabetes. All participants experienced controlling the dependence of self-management activities. They must depend on the effort in a regular diet, exercise, control blood sugar and injecting insulin. Efforts should be made to achieve normal blood sugar condition. Participant RJ and KN brought another option to help achieve the blood sugar in a normal condition by thinking positive thoughts. They did not do this because they believed that the psychological conditions influenced their physical condition. Being dependence was also experienced by participant, and expecting having good parents, peers, boyfriends, and teachers. Their dependence is more to the wish of being reminded of their diabetes management.

\subsection{Living with an unwanted self while alone}

Another theme that appeared in all participants is living with an unwanted self. This theme appeared because the diabetes caused them suffered, and eventually they were trying to reject the pain and the change, experiencing internal conflict, and rejecting the real condition. 


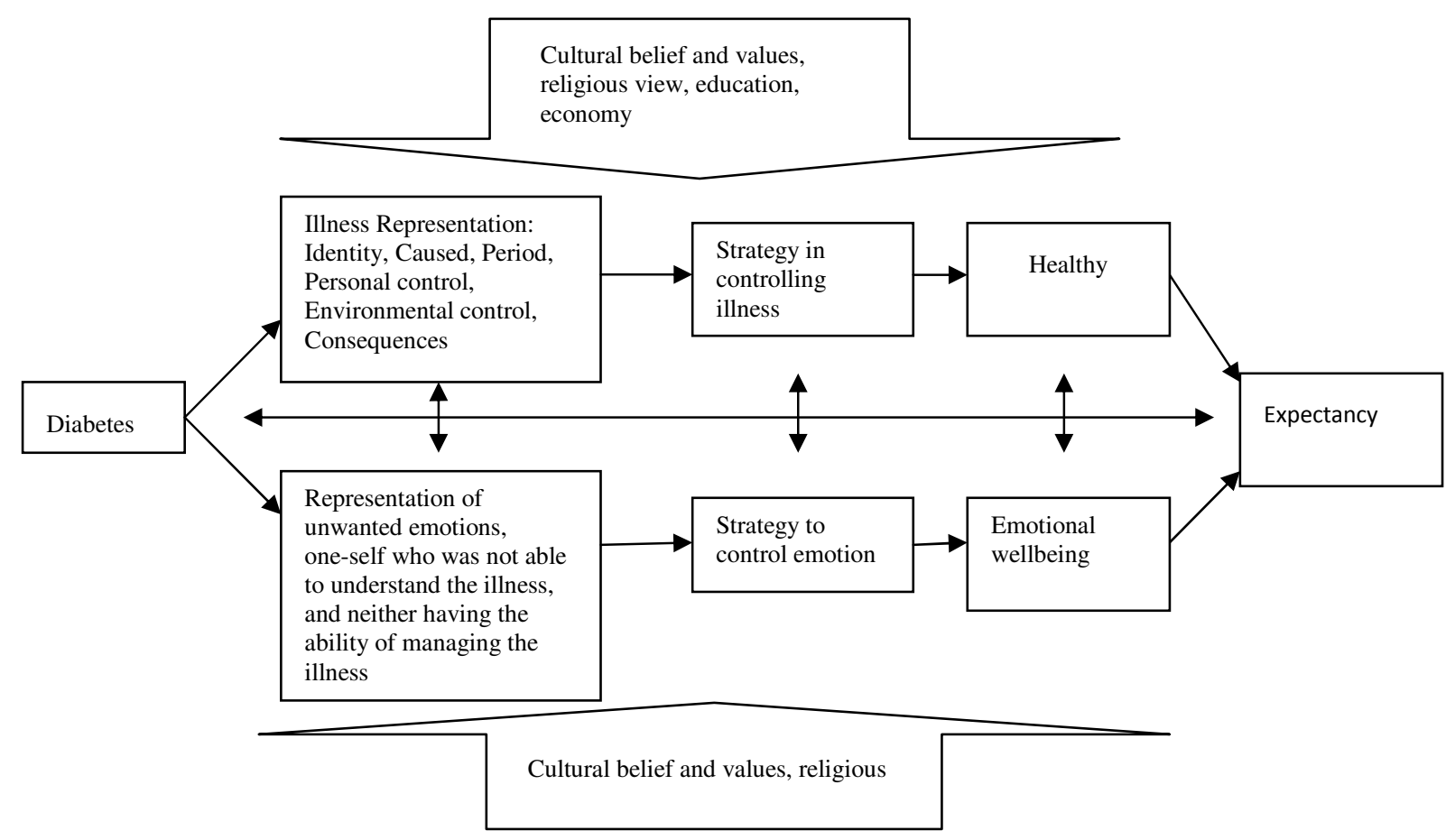

Diagram 1. Dynamics of pain self-management behaviors and adolescent illness representations of type 1 diabetes mellitus

\subsection{Living with an unwanted self while being with others}

The diabetic condition of all participants also brought consequences while they are with others in his/her environment. The social consequence that they experience is often destructive. Parents' attention and fear towards the adolescents' ability to maintain diabetes management will impact towards the parent's poor ability in providing support for adolescents' autonomy in effectively doing self-management (Dashiff, Vance, Abdullatif, \& Wallander, 2008). Parents who, at the beginning, did direct monitoring and directing their child's diabetes management would end up with negative emotion. Emotional expressions that were frequently shown were over involvement and over protective. Parents, especially mothers, tend to control activities and food consumptions of participants. KN's mother has even planned the future life. This makes them feel like a child.

\section{Conclusions and recommendation}

Adolescent with type 1 diabetes have self-management experience which is dominated by several themes. These themes are participants' subjective illness representation, feeling of unwanted, and lack of understanding in the knowledge. These themes influence one another in the form of participants' behavior in managing and controlling their illness in order to achieve physical and emotional wellbeing. Components in the representation of subjective pain that were found in the field were slightly different from existing components on the behavioral self-regulation model of illness and pain representations. The findings in the field showed that the control component differentiated into two components: personal control and environmental control.

Implementation of participants' self-management was not only done by participants themselves. Control and regulation were highly dependent on the mother as the primary caregiver of the participants. Participants' peer also has a role in the implementation of self-management. Participants' peer support can assist participants in 
adjusting to diabetes experience. On the other hand, Participant had difficulty in complying with self-management activities, especially the implementation of the diet when they are together with peers. These conditions create a strong autonomy that is required of the participants so that they would be able to face their peers in order to effectively do their diabetes management.

Results of this research may contribute to the design of clinical interventions for adolescents with type 1 diabetes. Interventions can be given in the form of education on type 1 diabetes and how family and peers can provide effective assistance in the implementation of diabetes self-management. Family therapy can be given to teens and parents to maximize the provision of support that is useful in the implementation of diabetes management. Family therapy can facilitate adolescents and parents in dealing with conflicts that arise during the implementation of the management of diabetes. Support group for fellow teens with type 1 diabetes and their parents can also be formed as a forum for sharing experiences. Limitation of this study is the limited number of female participants involved in the study. Adolescent girls and boys have different needs and experiences in interactions with peers. This situation could be a concern in future studies.

Acknowledgement: This study was part of an integrated study on Management Diabetes Mellitus supported through a Hibah Grant by the Faculty of Psychology, Universitas Gadjah Mada, Yogyakarta, Indonesia. (Hibah Payung Magister Profesi Psikologi, Fiscal Year 2011)

\section{References:}

Albery, I. P., \& Munafó, M. (2008). Key concepts in health psychology. London: Sage Publication.

Bean, D., Cundy, T., \& Petrie, K. (2007). Ethnic differences in illness perceptions, self-efficacy and diabetes self-care. Psychology and Health, 22(7), 787-811. <http://dx.doi.org/10.1080/14768320600976240>

Clarke, W. L. (2011). Behavioral challenges in the management of childhood diabetes. Journal of Diabetes Science and Technology, 5(2), 255-258.

Cohen S., Gottlieb B., \& Underwood, L. (2000). Social relationships and health. In Social support measurement and intervention. Oxford: Oxford University Press.

Cox, D. J., \& Gonder-Frederick, L. (1992). Major development in behavioral diabetes research. Journal of Consulting and Clinical Psychology, 60(4), 628-638. <http://dx.doi.org/10.1037/0022-006X.60.4.628>

Creswell, J. W. (1998). Qualitative inquiry and research design: Choosing among five traditions. USA: Sage Publications. Inc.

Dashiff, C., Vance, D., Abdullatif, H., \& Wallander, J. (2008). Parenting, autonomy and self-care of adolescents with Type 1 diabetes. Journal compilation Child: care, health and development, 35(1), 79-88. $<$ http://dx.doi.org/10.1111/j.1365-2214.2008.00892.x>

Dwiardiani, F. (2009). Effectivity of self-empowerment training to improve the compliance of adolescents with type 1 diabetes [In Indonesian]. Unpublished Masteral thesis, Universitas Gadjah Mada, Indonesia.

Edgar, K. A., \& Skinner, T. C. (2003). Illness representations and coping as predictors of emotional well-being in adolescents with type 1 diabetes. Journal of Pediatric Psychology, 28(27), 485-493. $<$ http://dx.doi.org/10.1093/jpepsy/jsg039>

Feifer, C., \& Tansman, M. (1999). Promoting psychology in diabetes primary care. Professional Psychology: Research and Practice, 30(1), 14-21. <http://dx.doi.org/10.1037/0735-7028.30.1.14>

Fisher, E. B., Delamater, A. M., Bertelson, A. D., \& Kirkley, B. G. (1982). Psychological factors in diabetes and its treatment. Journal of Consulting and Clinical Psychology, 50(6), 993-1003. $<$ http://dx.doi.org/10.1037/0022-006X.50.6.993>

Fisher, E. B., Earp, J. A., Maman, S., \& Zolotor, A. (2009). Cross-cultural and international adaptation of peer support for diabetes management. Family Practice-An International Journal, 10(1), 1-11. 
Asril dan, N. M. \& Yuniarti, K. W.

Fiske, S. T. (2004). Social beings: A core motives approach to social psychology. Hoboken, NJ: John Wiley and Sons.

Gois, C. J., Ferro, A. C., Santos, A. L., Sousa, F. P., Ouakinin, S. R., Carmo, I. D., \& Barbosa, A. F. (2010). Psychological adjustment to diabetes mellitus: Highlighting self-integration and self-regulation. Acta Diabetol, 1-8.

Gonder-Frederick, L. A., Fisher, C. D., Ritterband, L. M., Cox, D. J., Hou, L., DasGupta, A. A., \& Clark, W. L. (2006). Predictors of fear of hypoglycemia in adolescents with type 2 diabetes and their parents. Pediatric Diabetes, 7, 215-222. <http://dx.doi.org/10.1111/j.1399-5448.2006.00182.x>

Hagger, M. S., \& Orbell, S. (2003). A meta-analytic review of the common-sense model of illness representations. Psychology and Health, 18(2), 141-184. $<$ http://dx.doi.org/10.1080/088704403100081321>

Hains, A. A., Berlin, K. S., Davies, W. H., Parton, E. A., \& Alemzadeh, R. (2006). Attribution of adolescents with type 1 diabetes in social situation: Relationship with expected adherence, diabetes stress, and metabolic control. Diabetes Care, 29(4), 818-822. $<$ http://dx.doi.org/10.2337/diacare.29.04.06.dc05-1828>

Heisler, M. (2007). Overview of peer support models to improve diabetes self-management and clinical outcomes. Diabetes Spectrum, 20(4), 214-221. <http://dx.doi.org/10.2337/diaspect.20.4.214>

Hekler, E. B., Lambert, J., Leventhal, E., Leventhal, H., Jahn, E., \& Contrada, R. J. (2008). Commonsense illness beliefs, adherence behaviors, and hypertension control among African Americans. Journal Behavior Medic, 31, 391-400. <http://dx.doi.org/10.1007/s10865-008-9165-4>

Helgeson, V., \& Cohen, S. (1996). Social support and adjustment to cancer: reconciling descriptive, correlational, and intervention research. Health Psychology, 15(2), 135-148. $<$ http://dx.doi.org/10.1037/0278-6133.15.2.135>

Horne, R., \& Weinman, J. (2002). Self regulation and self management in asthma: Exploring the role of illness perception and treatment belief in explaining non adherence to preventer medication. Psychology and Health, 17(1), 17-32. <http://dx.doi.org/10.1080/08870440290001502>

Kaptein, A. A., Bijdterbosch, J., Scharloo, M., Hampson, S. E., Kroon, H. M., \& Kloppenburg, M. (2010). Using commonsense model illness perception to examine osteoarthritis: A 6-years longitudinal study. Health Psychology, 29(1), 56-64. <http://dx.doi.org/10.1037/a0017787>

Keogh, K. M., White, P., Smith, S. M., McGilloway, S., O’Dowd, T., \& Gibney, J. (2007). Study protocol changing illness perceptions in patients with poorly controlled type 2 diabetes, a randomised controlled trial of a family-based intervention: protocol and pilot study. BMC Family Practice, 8(36), 1-10.

Kim, U., Yang, K-S., \& Hwang, K-K. (2006). Indigenous and cultural psychology understanding people in context. USA: Springer.

Kovacs, M., Goldston, D., Obrosky, D. S., \& Bonar, L. K. (1997). Psychiatric disorders in youths with IDDM: Rates and risk factors. Diabetes Care, 20, 36-44. <http://dx.doi.org/10.2337/diacare.20.1.36>

Laffel, L. M. B., Connel, A., Vangsness, L., Goebel-Fabbri, A., Mansfield, A., \& Anderson, B. J. (2003). General quality of life in youth with type 1 diabetes. Diabetes care, 21(11), 3067-3073. $<$ http://dx.doi.org/10.2337/diacare.26.11.3067>

Lawson, V. L, Lyne, P. A, Bundy, C, \& Harvey, J. N. (2007). The role of illness perceptions, coping and evaluation in care-seeking among people with type 1 diabetes. Psychology and Health, 22(2), 175-191. $<\underline{\text { http://dx.doi.org/10.1080/14768320600774546> }}$

Lehmkuhl, H. D., Merlo, L. J., Devine, K., Gaines, J., Storch, E. A., Silverstein, J. H., \& Geffken, G. R. (2009). Perceptions of type 1 diabetes among affected youth and their peers. Journal Clinical Psychology Media Settings, 16, 209-215. <http://dx.doi.org/10.1007/s10880-009-9164-9>>

Lyons, E., \& Coyle, A. (2007). Analyzing qualitative data in psychology. London: Sage Publication Ltd.

Malik, J. A., \& Koot, H. M. (2009). Explaining the adjustment of adolescents with type 1 diabetes role of diabetes-specific and psychosocial factors. Diabetes Care, 32(5), 774-779. <http://dx.doi.org/10.2337/dc08-1306>

Mann, D. M., Ponieman, D., Leventhal, H., \& Halm, E. A. (2009). Predictor of adherence to diabetes medication: 
The dynamics of adolescent's self-management experience with Type 1 diabetes mellitus

The role of disease and medication belief. Journal Behavior Medic, 32, 278-284.

$<$ http://dx.doi.org/10.1007/s10865-009-9202-y>

Moss-Morris, R., Weinman, J., Petrie, K. J., Horne, R., Cameron, L. D., \& Buick, D. (2002). The revised illness perception questionnaire (IPQ-R). Journal Psychological and Health, 17(1), 1-16.

$<$ http://dx.doi.org/10.1080/08870440290001494>

Muhlisin, A., \& Rahmadiliyani, N. (2008). The relationship between knowledge on diabetes and its complications, and the behavior of control glicemic at a Community Health Center [In Indonesian]. Berita Ilmu Keperawatan, 64(2), 63-68.

Ogden, J. (2000). Health psychology: A text book (2 ${ }^{\text {nd }}$ ed.). Buckingham: Open University Press.

Patino, A. M., Sanchez, J., Edison, M., \& Delamater, A. M. (2005). Health beliefs model and regimen adherence in minority adolescents with type 1 diabetes. Journal of Pediatric, 30(6), 503-512.

Paul, G. M., Smith, S. M., Whitford, D. L., O'Shea, E., O'Kelly, F., \& O'Dowd, T. (2007). Study protocol peer support in type 2 diabetes: A randomised controlled trial in primary care with parallel economic and qualitative analyses: pilot study and protocol. BMC Family Practice, 8(45), 1-13.

Pendley, J. S., Kasmen, L. J., Miller, D. L., Donze, J., Swenson, C., \& Reeves, G. (2002). Peer and family support in children and adolescents with type 1 diabetes. Journal of Pediatric Psychology, 27(5), 429-438. <http://dx.doi.org/10.1093/jpepsy/27.5.429>

Poerwandari. (1998). Qualitative approach in research studies in psychology [In Indonesian]. Jakarta: Lembaga Pengembangan Sarana Pengukuran dan Pendidikan Universitas Indonesia.

Rudijianto, A. (2009). Management diabetes [In Indonesian]. An unpublished paper presented at the conference of World of Diabetes Day.

Santrock, J. W. (2000). Cognitive developmental in young adults. Boston, MA: McGraw-Hill.

Smith, J. A., Flowers, P., \& Larkin, M. (2009). Interpretative phenomenological analysis. Theory, method, and research. London: Sage Publication.

Taylor, S. E. (2006). Health psychology (6 ${ }^{\text {th }}$ ed.). London: McGraw-Hill International Edition.

Timmers, L., Thong, M., Dekker, F. W, Boeschoten, E. W., Heijmans, M., Rijken, M., Weinman, J., \& Kaptein, A. (2008). Illness perceptions in dialysis patients and their association with quality of life. Psychology and Health, 23(6), 679-690. <http://dx.doi.org/10.1080/14768320701246535>

Tjokroprawiro. (2004). Living healthy and happy with diabetes [In Indonesian]. Jakarta: Penerbit PT Gramedia Pustaka Utama.

World Health Organization. (1999). Definition diagnosis and classification of diabetes mellitus and its complication. Department of Noncommunicable Disease Surveillance.

Yuniarti, K. W. (2010). Knowledge is not enough. The discrepancy between hygiene-related knowledge and practices among mother of children with diarrhea in Indonesia. Germany: Lambert Academic Publishing GmbH \& Co. KG. 
Asril dan, N. M. \& Yuniarti, K. W. 